\title{
Conference and workshops Montreal, Canada 2008
}

\author{
Ferdynand Barbasiewicz* \\ Molecular biologists, Poland \\ *Corresponding author: Ferdynand Barbasiewicz, Molecular biologists, Poland
}

Submission: 涀 June 12, 2018; Published: 眥 June 20, 2018

\section{Introduction}

Most of the participants of the last RAC (The Reflexology Association of Canada) Conference remember well the sensation caused during workshops run by Dr Ferdynand Barbasiewicz, a psychologist and neurophysiologist from Poland. There is still interest and discussions are being held on the therapy that he presented.

Dr Barbasiewicz's work and achievements were discovered by one of the members of the Association, Dr Bazyli Pawluczuk, who invited Dr Barbasiewicz to share his achievements and successes at the forum of the conference of reflexologists in Montreal in November 2008. The workshops run by Dr Barbasiewicz attracted approximately 100 attendants, among who was a lady in her sixties, wheelchair-bound for the last 18 years. She consented for Dr Barbasiewicz to demonstrate on her his unique therapy. (Her account can be found below).

Damage to the sciatic nerve sustained in an accident had caused a partial paralysis of her body beneath hips and had left her right foot completely inert. She had lost the feeling of touch and warmth in lower extremities and both her legs were cold and swollen.

Dr Barbasiewicz presented the principles of his method and stipulated that he could not guarantee the results of his therapy but if the woman agreed, he could check whether the damaged nerves showed signs of life and whether they could be regenerated.

To everybody's surprise Dr Barbasiewicz did the impossible by means of his method. The woman was able to stand on her feet and make a few steps forward without any pain. Every next day Dr Barbasiewicz continued his therapy. On the second day a reflex to touch, warmth and movement appeared in the big toe of the foot which regained its normal position having previously dropped and been immobile. At the end of the second day the woman left her wheelchair and walked up the stairs to the first floor. On the fourth day the swelling on her legs was gone; the legs became warm, which enabled her to carefully walk around the room without any assistance.

The method presented by Dr Barbasiewicz is the result of 50 years of intensive research in the field of neurophysiology and psychosomatic disorders of the nervous system. The uniqueness of this therapy stems from making use of exceptionally effective, non-invasive stimulation of nerve receptors scattered on the skin. It is done thanks to specially shaped small metal rods with sharp endings similar in appearance to nails (clavus=nail), hence the name clavitherapy, dermoneural-reflexology, clavitherapy. Within a few minutes of the stimulation in the form of compression inflicted by means of clavuses, there is a strong excitation of the brain leading to mobilization of the immunological system and initiation of the metabolic chain reactions in cells on every endogenous level in molecular and submolecular structures. As a result, almost instant changes are observed in the flow of bioelectrical impulses on the surface of cell membrane. Neurotransmitters are activated in the plasma, which leads to detoxication of nerves and regeneration of the neurolemma around the damaged nervous fibers.

Lost conduction of nerve signals due to demyelinization or embolism in the brain is often restored during stimulation lasting a few hours. During the biostimulation of nerve receptors by means of clavitherapy a patient first experiences a strong burning pain, which in the course of regeneration of the neurolemma vanishes with the healing process taking place.

In the above described case reconstruction of nerve connections and resuming of the lost bioelectrical signal in the damaged sciatic nerve and peripheral nerves can be named a miracle revealing that through skillful stimulation of nerve receptors on the skin human organism is capable of performing full regeneration and selfhealing. 
Creative Commons Attribution 4.0 International License

\begin{tabular}{ll} 
RMES $\begin{array}{l}\text { Researchin } \\
\text { Medical } 8 \\
\text { Engineering } \\
\text { Sclences }\end{array}$ & \multicolumn{1}{c}{ Research in Medical \& Engineering Sciences } \\
Benefits of Publishing with us
\end{tabular}

